\title{
OCCUPATIONS AND IDEOLOGIES: \\ A CONCEPTUAL ORIENTATION
}

Reid A. Luhman

University of Kansas

One of the major problems in the sociology of occupations has been a tendency to accept concepts stemming from occupations themselves rather than from the development of a body of concepts logically separated from those ideological considerations. Occupational division of labor is accepted as a "given" in the course of much analysis with little attempt made to either explain the genesis of such a development or its subsequent interrelations with other elements of social systems. Much of this problem can be alleviated through an emphasis on process models which make conceptual distinctions between social and non-social factors affecting occupations.

Occupations (or divided human work) form an elaborate system which ultimately derives from man's relation to his environment. Men are confronted by objective problems of survival with which they must deal. Such dealings contain a knowledge-technology factor in an objective sense (i.e., distinct from social meaning which may be imputed to that knowledge and technology). The division and allocation of knowledge and technology among occupations is the social factor - the factor which in this model is labeled ideology. Ideology, the division and allocation of knowledge and technology in a society, then interacts with the environment affecting, first, the conceptualization of environmental problems and, secondly, the division of tasks with regard to those problems. As a result, not only is the social division of labor itself an ideology, but the environment in turn becomes categorized in terms of those conceptualizations.

"God, when he gave the World in common to all Mankind, commanded Man also to labour, and the penury of his condition required it of him."

John Locke

Had God allowed man to remain in the Garden of Eden, labor would never have become necessary. There would then be no "occupations" today nor would there be sociologists to study them. Since there are and we do, however, there is perhaps some point in restating a fundamental necessity involved in work. As Locke suggests, the "penury of his condition" requires man to wrest his survival from his environment or, put in more modern terms, the energy needs of the organism require some means of procurement. Man's environment requires certain things of him if he is to survive. One of the means employed by man has been the formation of often very elaborate societies to aid in this effort, and these societles in turn have come to give new meaning and direction to the basic business of work. It is important, however, in the analysis of work to place the social meaning that men give to their activities in proper perspective. One of the major stumbling blocks in the sociology of work has been the conceptual confusion that has resulted from the contradictions with this social meaning. As Karl Marx once observed, even the corner grocer knows the difference between what man is and what he claims to be. Marx was lamenting this inability in historians, but perhaps sociologists have something to learn as well. Using conceptual formulations generated from occupational development (such as "professional") often creates highly biased ideological analysis. It is the purpose of this paper to propose a different conceptual orientation to occupations in the form of a process model which accounts for Marx's distinction on the one hand and re-emphasizes environmental demands on the other.

K.J.S. VII, 2 
An occupation is basically a goal-directed human activity. ${ }^{1}$ The question which immediately arises is where do specific goals come from and why are they approached through specific activities? The initial stimulation for such activities is suggested in the opening quotation from John Locke -- that one may look directly for survival difficulties in man's environment. This statement does not appear that profound, as it is obvious that man must eat and find shelter if he is to survive, but the apparent simplicity is misleading. Not only do environments change over time of their own accord, but man's intervention has a very definite effect. As a group of people interact with their environment (specifically, removing things from it), ecological relations must change and this change may require some social adaptation. Beyond this, of course, societies change over time and require either more or dif-. ferent things from their environments. Looking at the present ecological difficulties man is encountering, the importance of this variable for human society can hardly be over-stressed. Emile Durkheim (1933) perhaps stated ecological problems best in 1893.

Civilization is itself the necessary consequence of the changes which are produced in the volume and in the density of societies. If science, art, and economic activity develop, it is in accordance with a necessity which is imposed upon men. It is because there is, for them, no other way of living in the new conditions in which they have been placed. From the time that the number of individuals among whom social relations are established begins to increase, they can maintain themselves only by greater specialization, harder work, and intensification of their faculties.

I would suggest then that the nature of physical variables be re-examined in any at-tempt to explain societal change. The constantly changing interaction between human societies and their environments is the only logical starting point for such an explanation. ${ }^{2}$ However unfortunately, man must labor, but as he gives that labor social meaning, new variables are imposed upon the model.

The undertaking of an activity will inevitably lead in the direction of some form of technological development. Subsumed within this category is the development of computers as well as knowing where the best berries are or where the predatory animals are not. In short, technology is a means to the end of an activity and may be a physical tool, but however concrete or abstract the technology, it will always be a piece of knowledge. Subsequently, any degree of technological change carries with it a similar degree of knowledge specialization -- a specification of that which is "known" by the group involved. As this new specialization of knowledge confronts existing group processes, new social meaning is imposed upon that group's activities. It is this meaning that $I$ will call the ideological basis of human activity. 3 At any given time, this ideological basis contains a relatively formal goal system and a relatively formal "means" system -- those things which the group aspires to and accepted means for attempting to achieve those goals. Understandably, an ideological basis will affect both the perception of "problems" in dealing with the environment as weil as the categorization of those dealings into specific activities. In trying to explain the creation of human activities, therefore, we must consider both environmental demands upon a society as well as social perceptions that have arisen from previous dealings with the environment. The model I am suggesting, now in a very general form, would perhaps be more clear if presented schematically. 
Figure 1. Schematic representation of general social iategration model.

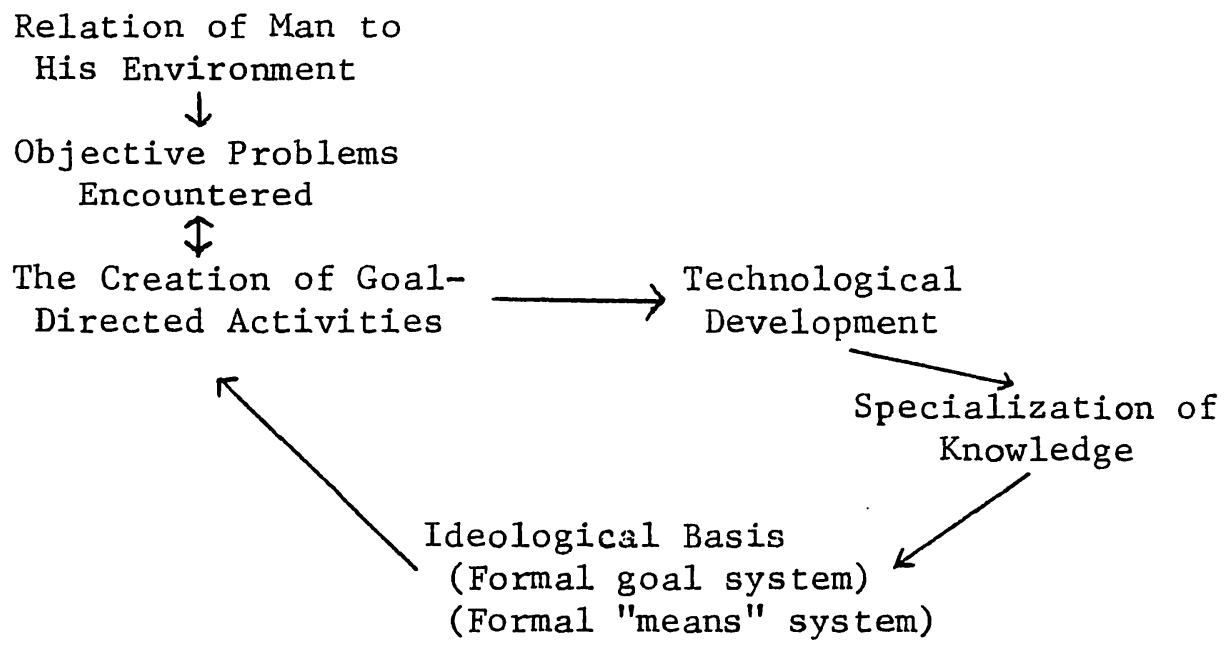

Visible change in a social system would be reflected in the ideological basis for that system. As a society deals with its environment over time (thus repeatedly running through the model), activities would become divided and formalized as ideology and the various segments of society that become delineated in any complex system would begin to take shape. In essence, then, the kinds of problems that groups of people encounter as their environmental relations change, become channeled into increasingly specific activities and become labeled as such, hence the growth of governments, market systems, and the like. Again, looking to Durkheim, such specialization and formalization become necessary over time in an adaptive sense. The intention for the general model presented thus far is to provide a basic core (or conceptual approach) for detailed analysis of highly specific activities as they occur in the more complex forms of social organization. The general model is a processual interaction model designed as a tool in understanding increasing specificity in human activities. The problem, of course, is that as one activity becomes more specific, all others by definition must also become more specific -- hence a complex system of social organization. As stated, the purpose of this paper is to examine a highly specialized form of human activity which has been formalized and labeled in the ideological basis of Western society as an occupation. It is necessary to expand the original model to account for the elaborate and confusing relations which arise within occupations, between occupations, and between occupations and other specialized activities which affect them. Occupations, once established, change internally. Medicine, for example, has specialized into many separate occupations all subsumed under the medical field. As occupations change internally, they are affected by other occupations which, of course, are changing internally simultaneously. As occupations inter-relate, they are also affected by other social structures. The model presented here does not presume to clarify these relations totally, but rather to emphasize the necessity of viewing occupations or occupational segments not in a social vacuum and hopefully to suggest ways in which these relations may be successfully conceptualized. 
Figure 2. Expanded occupational model.

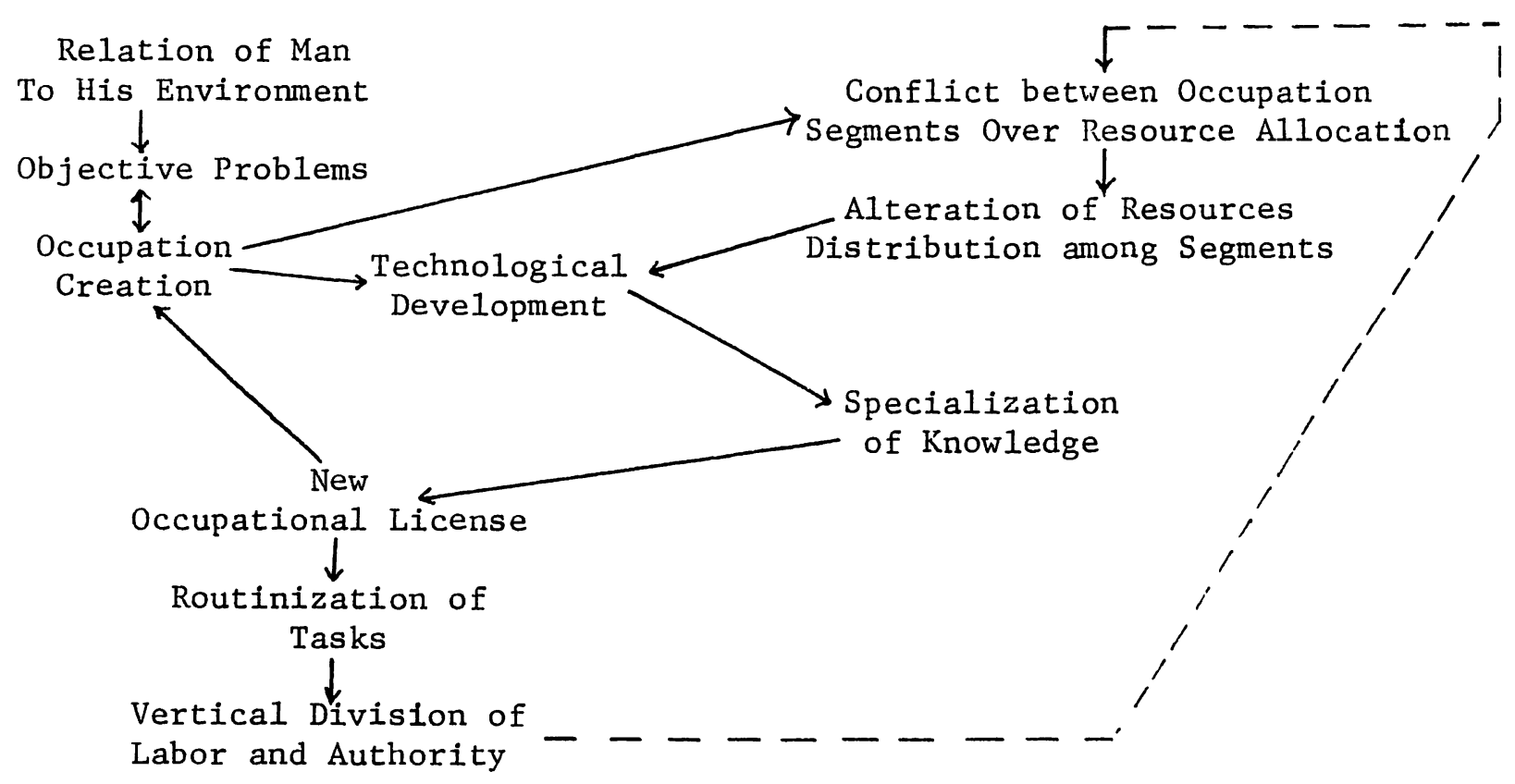

This model contains the more general model in its entirety with one change in the wording to emphasize the more complex inter-relations mentioned in the preceding discussion. Since an occupation is but one of many activities occurring in a social system, its ideological basis takes on the character of "license," or the "right" to engage in certain activities in a certain way. As an occupation becomes formalized, its "means" and "goals" also become more formalized and highly dependent upon other formalized activities (most notably, government and other occupations). The idea of license suggests that either some agreement or some deception (or both) exists as to exactly what an occupation is engaged in and why. Working toward "correct" goals through "correct" means in an occupation makes up the shared "definition of the situation" -that definition which, as suggested by $W$. I. Thomas, is both so very subtle and very important in any social situation. The important point here is that the ideological basis which underlies an occupation and delineates its activities from those of other occupations also delineates the world of objective problems in the environment. Medicine, for instance, consists of the right to cut into bodies and put drugs into bodies with the goal of Improving the health of the organism. Only the formalized occupation of medicine has the license to engage in these activities, and those new problems which are successfully labeled "health of the organism" by the occupation are then delegated to that occupation formally. In this way, the world of objective problems is invariably conceptualized and ultimately dealt with according to a prevailing division of licenses among occupations. ${ }^{4}$ The formation of new occupations (or segments of old occupations which is more often the case) is thus the product of objective problems encountered in dealing with the environment and the ways in which those problems had previously been divided among other occupations.

Moving outside the core of the model, we enter two outside loops which are designed to illustrate shifting authority relations and resource allocations both between and within occupational groups. As the activities of occupational groups become more formalized, so do relations between them. The change in any given occupational group cannot be explained without first examining concomitant changes in inter-occupation relations. 
As occupations become more formal, the specialization of knowledge becomes a highly important factor. A specialized body of knowledge buffers an occupational group from outside evaluation. The greater the knowledge specialization, the greater the insulation. This factor becomes important when hierarchical authority relations exist within and between occupations. Such authority relations depend, in part, upon evaluation of activities carried out under that authority. If this evaluation is threatened through increasing specialization in an occupation (thus minimizing possibilities of evaluation), some degree of power will ultimately pass over to that specialized occupation, thus stimulating directed technological advancement and increasing knowledge specialization. If authority relations are conceptualized as a vertical flow (as is suggested by standard organization charts for formal organizations), a specialization of knowledge creates a horizontal flow across the authority relations which act as a block across the line of flow.

Figure 3. Horizontal division of labor through knowledge specialization.

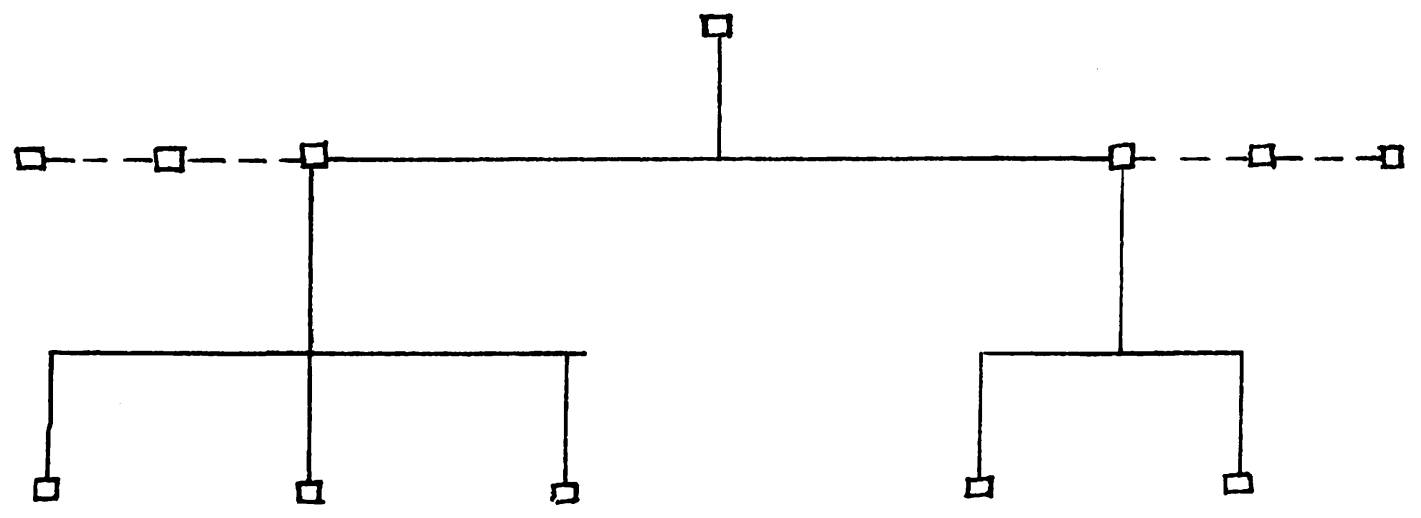

This is perhaps most clearly observed in the organization charts of general hospitals in which the physician, long since a specialized occupacion, is formally placed outside the normal authority flow in the organization.

Figure 4. Schematic diagram of general hospital organization.

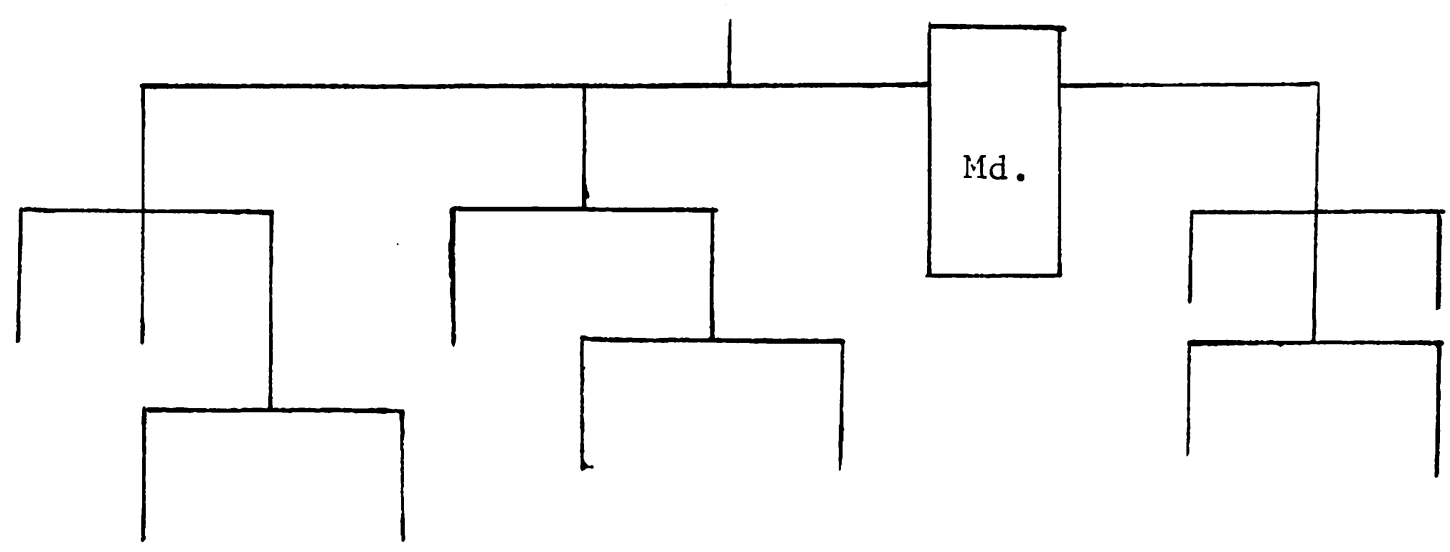

While the base of authority for "professional" occupations such as medicine has traditionally been viewed as charismatic with a factor called "expertise" of crucial importance, there appears to be (as Eliot Friedson, 1970 has suggested) an "institutionalized expertise" which exists between an occupation and its institutional (or formal) environment. In other words, it is an expertise gained through the control of authority relations within an institutional setting. This type of control becomes most visible in (and, in part, an effect of) the formation of "specialist communication 
channels" between occupations through which standard lines of authority and communication can be bypassed with tacit approval by all concerned. As Victor Thompson has pointed out, standard communication channels are not only undesirable for a specialized occupation within an organization, but they are also technically impractical from the standpoint of organizational goals -- again, suggested by the necessity of such channels in modern hospitals (Thompson, 1961: 86). The source of these channels, however, lies in a knowledge specialization which allows for changing authority relations. As Friedson (1961: 79) has observed, the lack of communication with patients in hospitals (which is usually attributed to the formal organization) is a direct result of the physician's position within that organization.

Everett Hughes (1958: 58-61) has pointed out that all occupations develop a ritual of activities over time. As mentioned earlier, license determines both "right" and "wrong" ways of doing things, and it is important for any emerging specialty to standardize tasks for a number of reasons. First, as Hughes (1958: 78-9) suggested, a group must maintain some sense of identity in its activities. If a specialty is to become formalized, it must have some sense of what it, as a group, is doing. Second, and perhaps more importantly, it must continually control evaluation of mistakes which are persistently present in its activity. If it can be asserted by a group that any particular one of its members has proceeded in line with the knowledge that they, as a group, possess, that member cannot be held accountable for the results of his actions. This protection is, of course, directly in line with the inability of others to evaluate results through an inability to evaluate means to those results. As a result of this type of protection, however, the group is forced to essentially routinize many of its tasks.

The formation of a new license (or ideological basis) for a specialty inevitably carries with it a number of either boring or time consuming tasks which appear in the practice of that new knowledge. Many of these tasks can be delegated by the specialty to other persons not in the specialty. Going back to the model, just as a new horizontal division of labor is being formed from the old vertical hierarchy in the occupation, a new vertical hierarchy is created beneath the new specialty.

Figure 5. Routinization of tasks under a specialized occupation.
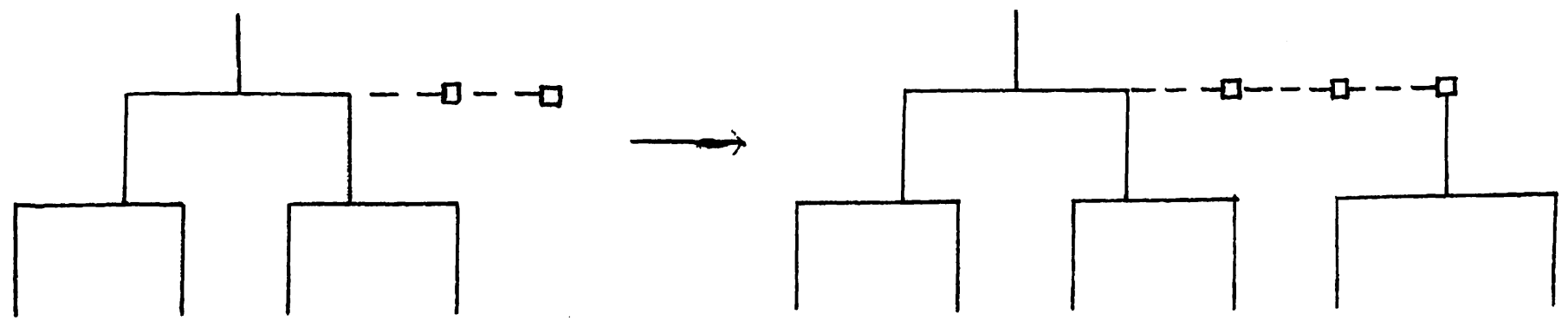

Authority and communication channels which had been cut through the formation of that specialty are now controlled and directed downward by the specialty. In other words, there is continual reshuffling within an occupational authority hierarchy based on changes occurring through a specialization of knowledge. And as this new vertical hierarchy forms, there is always the possibility that these new groups who enter the field of resource allocation might gain access to new knowledge and specialize under the specialties, delegating their new tasks, and so forth. Should this happen, they may well be co-opted into the previous specialty. While this is a hypothetical possibility (as indicated by the dotted line on the model), the central issue here lies in the relativity of different segments of an occupation to each other. There is nothing eternal in the specialization of knowledge, and the acquisition of knowledge itself should not be conceptualized as always moving upward, 
away from that knowledge which has already been gathered. There is a pragmatic sense of control over resources operating here, and while resources are more difficult to get at the lower levels of an occupational hierarchy under any given allocation system, a significant change in the nature of objective problems could conceivably stimulate a specialization of knowledge at those lower levels.

It has been the intent of this paper to provide a unified conceptual orientation for the sociological study of occupations. Due to space limitations and the very general nature of the orientation, little attempt was made at application of the model. It is hoped, rather, the presentation will stimulate some rethinking of conceptual meaning in the field of occupations. Without some cohesive framework or model to direct research through the maze of social relationships that have grown from the division of labor in society, that research will lack the unity that should characterize social scientific inquiry.

\section{Footnotes}

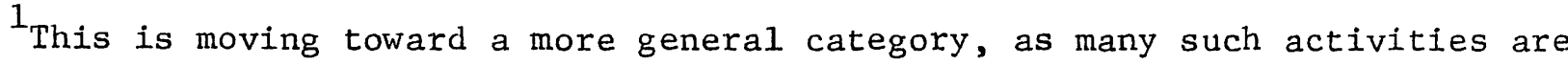
not labeled occupations, but this step is necessary to get beyond the confusion of beginning with a highly complex division of labor.

2

Clearly, if explanation is considered to include the genesis of that which is to be explained, a sociological explanation should have its foundation in some fundamental element which at least initially occurs outside the social world. A "given" is always relative to a perceived universe in scientific inquiry, but its use in explanation as a "given" must be consistent with the conceptual approach to the rest of the universe.

3It is assumed here that no forms of social organization are either "right" or sacred -- that man creates his goals and defines ways of accomplishing those goals, with future goal and activity creation affected by earlier social definitions. As such, the way in which a people conceptualize their activities can be viewed as an ideology -- a belief system which, from the perspective of change, is arbitrary.

${ }^{4}$ The way in which the world is delegated to different occupations is a direct result of the development that occurs in the ideological basis (or division of licence) over time. When knowledge specializes, that particular piece of the "known" is postulated to extend into an indefinite piece of the unknown with the assumption that any given division of labor in a given time will remain more or less constant. By way of analogy, this is very similar to the granting of land to the first American colonists by the British Crown. That piece of America along the Atlantic Ocean was the known and it was divided among various grants, but the assumption was that the grants would run ocean to ocean, however far that might be. As the unknown case to be explored, new forms of social organization (which, of course, included new divisions of property) were forced upon the situation. In similar manner, as suggested in the body of the paper, that which is medical is already delineated and delegated to a particular occupation even though future discoveries may suggest a radically different division of license. As suggested by the model, there is a slight lag here as license is the last thing to be affected tinrough environmental and technological change. 


\section{References}

Durkheim, Emile

1933 The Division of Labor in Society. George Simpson (trans.). New York: The Free Press.

Friedson, Eliot

1970 "Dominant professions, bureaucracy, and client services." Pp. 71-92. in Rosengren and Lefton (eds.), Organizations and Clients. Columbus, Ohio: Charles E. Merrill Publishing Co.

Hughes, Everett

1958 Men and Their Work. Glencoe, Illinois: Free Press.

Thompson, Victor

1961 Modern Organization. New York: Knopf. 